\title{
Dramaturgia femenina latinoamericana: Queiroz, Gambaro, Stranger
}

Graciela Ravetti***

Sara Rojo***

RESUMEN: Este artículo es un comentario a la Antología bilingïe de dramaturgia de mujeres latinoamericanas escrita por nosotras durante 1995-1996. La antología escrita en portugués-español consiste en un estudio de tres piezas: $A$ beata Maria do Egito de Rachel de Queiroz, Del sol naciente de Griselda Gambaro y Cariño malo de Inés Margarita Stranger. El artículo reflexiona sobre la fundamentación teórica del trabajo realizado.

Este trabajo es um comentario al libro que escribimos, en 1995-1996. Se trata de una antología que consta de tres piezas de dramaturgas latinoamericanas y de estudios teóricos de análisis de las mismas. El libro tiene un fuerte trabajo de traducción ya que todos los textos fueron editados en español y en portugués, lo cual significó una tarea esforzada y compartida con otros colegas y estudiantes. ' El hecho de que el trabajo sea bilingüe tiene un peso ideológico

\footnotetext{
: Recebido para publicação em julho de 1996.

*: Professoras Adjuntas de Língua e Literatura Espanholas do Departamento de Letras Românicas da Faculdade de Letras da UFMG.

1 Prosolina Alves Marra, Renato de Mello, Denise A. Pedron y Rodrigo V. Machado.
}

CALIGRAMA - Belo Horizonte, 2:103-112 - novembro/1997 
en la dirección de la integración latinoamericana ya que, tradicionalmente, los estudios que se decían latinoamericanos no incluían textos brasileños. Este aspecto nos parece extremamente importante en un minuto en que se habla de globalización, de disolución de las fronteras; pero en el cual aún subsisten prejuicios en torno a la integración de nuestras culturas y, por derivación natural, de nuestras lenguas.

Nuestro propósito inicial fue el de colaborar de alguna manera con la crítica feminista en Latinoamérica intentando establecer la diferencia - teórica y práctica - en un ámbito específico - el latinoamericano. Ámbito que no sólo conlleva una carga de discurso crítico patriarcal autoritario, monológico y controlador, sino también todo lo que deriva de un reciente pasado de colonización. Pensamos que estas marcas no son posibles de soslayar si se quieren entender los movimientos locales y el peso de la cultura occidental impuesta.

Perseguimos este objetivo trabajando con el concepto de género, siguiendo algunas sendas ya trilladas por la crítica feminista contemporánea. Una de las líneas que más nos interesó fue la que piensa el género como una construcción cultural en proceso. Sobre todo, cuando trabaja con la idea de que no se trata de incorporar piezas en el juego de poderes de la llamada sociedad occidental, sino de re-escribir la historia - literaria, en nuestro caso. Este movimiento significa incluir elementos que no pueden menos que desestructurar el orden establecido y obligar a levantar uno nuevo, que se construye paso a paso con la participación de las llamadas "expresiones de lo Otro".

La teoría que sirvió de apoyo a los estudios críticos conjugó aportes del feminismo antropológico, de la teorización sobre imaginarios sociales, de la desconstrucción, de la semiótica y de los llamados "estudios subalternos", en la línea de la postcolonialidad. Los estudios subalternos son definidos por Mallon, como estudios del "Tercer Mundo": "anticolonial and politically radical yet conversant with the latest in textual analysis and postmodern methods" . En ese contexto se entiende como subalterno cualquier sujeto subordinado y, por ende, su discurso: "in terms of class, caste, age, gender and office or in any other way." ${ }^{3}$ Es por eso que esta investigación, pensada desde una perspectiva latinoamericanista, se focaliza en la producción literaria de la mujer, específicamente en la dramática.

2 MALLON, Florencia., 1994, p. 1493.

. 3 Ibiden, p. 1494. 
Es en base a estos criterios que seleccionamos a Rachel de Queiroz en Brasil, a Griselda Gambaro en la Argentina y a María Inés Stranger en Chile. Pensamos que todas ellas han contribuido, desde enunciaciones y problemáticas diferentes, al proceso de descolonización y desconstrucción del canon patriarcal en América Latina. Estas escritoras, en épocas y países distintos-semejantes, han creado sus propias maneras de reapropiarse del lenguaje dramático y de reescribir la historia y la cultura; han cuestionado las imágenes de la mujer y dado a luz otras más representativas del estatus aspirado; han buscado, por sobre todas las cosas, una palabra que se escuche como propia. Este escribir construyendo una voz y un pensamiento se convierte en un quehacer subversivo dentro de sociedades que, como las nuestras, tienen una formación cultural postcolonial y están asentadas sobre un lenguaje masculino donde la mujer ocupa ese lugar de "subalternidad".

Nuestro trabajo teórico se ocupa, entonces, en una primera instancia, tanto de la enunciación ficcional como de la crítica: nos ocupamos de descubrir los signos enunciativos de las autoras pero también de dejar claro nuestro propio punto de enunciación. Ese camino nos condujo a un abordaje necesariamente plural, donde la diversidad de las enunciaciones, incluso nuestras, no puede menos que producir un discurso obligatoriamente diferente y diferenciador, fuente de controversia y oposición al discurso oficial monológico y excluyente. Buscamos un modo de hacer crítica que clialogue con el texto ficcional y con la historia sin pretender que sea la nuestra "la última palabra del discurso" o nuestra reflexión "la alternativa" al canon vigente. Pensamos que la escritura de las mujeres tiene que ser recuperada no como un simple agregado a la historia, sino que como un modificador dialéctico de la misma: leer y analizar los textos femeninos en diálogo, a veces incluso violento, con los parámetros vigentes, implica necesariamente la modificación de los mismos.

A estas preocupaciones se sumaron las que dependían de caracterizar la especificidad que representa el oficio de escribir teatro, de ser dramaturgas. El teatro significa, en todas sus vertientes, exponer la palabra, llevar al ámbito público ciertas connotaciones de revelación de la intimidad en voz alta. El teatro tiene la magia de permitir la recepción directa del público y es eso lo que sucedió con las tres piezas que escogimos en diferentes momentos de la historia: Raquel de Queiroz expuso la problemática del mesianismo en los años 50, pero con voz de mujer en una sociedad, la brasileña, que tiene marcas en ambos niveles. Griselda Gambaro en los 80 , desde un personaje femenino, habla de la liberación del poder y del autoritarismo en un país, Argentina, que ha vivido bajo dictaduras. Inés Margarita Stranger, en los 90, intenta reconstruir una identidad femenina desde parámetros diferentes a los impuestos por el 
imaginario colectivo de una sociedad patriarcal, la chilena. Se trata de decir para ser oída dentro de sociedades poco acostumbradas a la "palabra de mujer" y que todavía pretenden, sin contrapartida, "la castidad" en la mujer. Alfonsina Storni ya lo decía:

\section{Tú que el esqueleto \\ Conservas intacto \\ No sé todavía \\ Por cuáles milagros, \\ Me pretendes blanca \\ (Dios te lo perdone), \\ Me pretendes casta \\ (Dios te lo perdone) \\ iMe pretendes alba! ${ }^{+}$}

Otro aspecto tratado fue el de la posición que ocupan estos textos en los movimientos definidos como pertenecientes a la modernidad y a la postmodernidad. Las tres autoras elegidas se ubican, como decíamos anteriormente, en diferentes momentos y espacios del siglo XX.

Rachel de Queiroz, con A Beata Maria do Egito trabaja con signos provenientes de la historia y de la sociología brasileñas. Incluye una figura de mujer que, imaginada en contrapunto a una leyenda cristiana tradicional, se yergue como líder a partir de las coordenadas del autoritarismo y del patriarcalismo en el encuadre de un movimiento mesiánico, tradicionalmente dirigido por hombres. En ese sentido, responde a la estructuración básica de la modernidad que, como dirían T.S. Eliot u Octavio Paz, se levanta aunando la tradición y el talento individual, transformando lo que está en el pasado - como diría Borges sobre los precursores - de acuerdo con los propósitos de la obra moderna. La tradición es, en la modernidad, una conquista. En A Beata Maria do Egito, la organización popular bajo la influencia poderosa de un líder, pone en evidencia - y los parlamentos de la Beata así lo enfatizan - las contradicciones de la modernidad en un país postcolonial como Brasil: una modernización que se erige sobre el hambre y la discriminación de amplios sectores de la población. La mujer, la Beata, contrariando el papel tradicional que la sociedad le asignaba en esos años, es quien encarna los planteamientos de resistencia a la ley escrita del poder y llama a la transgresión de lo establecido. Enarbola la lucha, tanto en lo social como en lo personal, atentando contra el orden político esta-

4 STORN1, Alfonsina, 1977, pp. 30-31. 
blecido - gobierno - tanto como contra el orden social - familia. De esta manera, los discursos del poder son desafiados por un sujeto subyugado, subalterno. Ella, además de ser mujer, no pertenece a la clase privilegiada (no tiene ni el sexo que detenta el poder, ni la "cuna" que lo sustenta). La Beata es un personaje femenino que se estructura a contrapelo de los estereotipos de definición del género: tiene un objetivo externo claro y preciso por el cual lucha, hace uso de estrategias tradicionales femeninas pero para conseguir sus objetivos - seducción a través del cuerpo - y, lo que es peor y más confuso para el sistema, sus propósitos no están atados a los clásicos preconceptos, también tradicionales, como virginidad y maternidad. La seducción le sirve para conseguir lo que desea y si el hombre pierde esa batalla, no es tanto por el poder de esa seducción sino más bien porque él sí se deja llevar por ideas cristalizadas sobre lo que es o no una mujer. El Teniente cree firmemente que, después de una relación sexual, una mujer virgen como la Beata, se entregará al hombre. Pero, permanentemente, el discurso de la Beata se estructura bajo otros parámetros, que tienen más que ver con la fuerza que la impulsa a la construcción de su "utopía" que con el imaginario masculino. Se trata, así, de un discurso que es al mismo tiempo que una acción concreta de liberación, una problematización de lo que se da por sabido.

Griselda Gambaro, con Del sol naciente imprime a su obra unà militancia alegórica, dentro de los parámetros de la postmodernidad, en los que lo genérico y lo político se configuran en una trama en la que el espácio se actualiza con signos japoneses. En el mundo globalizado, lo privado aparece como signo de discusión de lo público. El ama (japonesa, pero con rasgos apenas insinuados) desea ardientemente tener sillones para decorar la casa para su propia comodidad como para la de las visitas. Lo que puede leerse como un movimiento, en primer lugar, de fascinación con respecto a las tentaciones del mercádo globalizado, y en segundo lugar, de renuncia a lo específico de su cultura. Este último aspecto puede analizarse, gráficamente, a partir del desdibujamiento de sus rasgos orientales. Dice Marta Contreras: "La escritura novelesca de Griselda Gambaro así como su teatro se inserta plenamente en la contemporaneidad literaria que propone la escritura como un laboratorio de diagnosis social."5 Suki, la cortesana japonesa, es la imagen de una mujer cuyo cuerpo sería, según el canon social, propiedad de todos, abierto al uso y al abuso, comercializado, vendido, prostituido. Todo esto en el territorio de la "clandestinidad", de lo que no forma parte de los valores sociales que se postulan en la

5 CONTRERAS, Marta, 1987, pp. 199-200.

CALIGRAMA - Belo Horizonte, 2:103-112 - novembro/1997 
Iglesia o en el Estado, pero que se "toleran" en nombre de ciertas ambiguas y no oficiales necesidades "masculinas". Sin embargo, Suki, marginalizada desde todos los ángulos, es la voz de la compasión y de la lucha contra lo que representa la tiranía, la opresión, la sumisión, la explotación de unos por los otros; es la voz que rescata la cultura popular tocando incansablemente las cuerdas de su biwa. Ella es quien, en última instancia, decide romper su estigma, haciendo el uso que desea de su cuerpo; es quien, finalmente, se impone frente a las emociones desbordadas de los que no pueden pensar en un mundo igualitario y humano - Obán — ; es quien opta por construir un nuevo "habitat". La enfermedad y la muerte se configuran a partir de recursos de tipo fantástico, absurdos o grotescos, en que los muertos vuelven, sin que la muerte violenta que prescribe el sistema para casos de "marginales que obstaculizan" se pueda concretizar. Si en la Historia la violencia mata efectivamente, en $\mathrm{Del}$ Sol naciente no es suficiente para exterminar personas, por débiles que parezcan. De esta manera, estos seres se convierten en símbolo del pueblo que renace. La utopía está presente y, por fuerte que sea el poder, los excluidos no podrán ser destruidos.

Que las víctimas no cesen de volver es un tópico común en estas obras: en Cariño malo, se habla de las voces insistentes y enloquecedoras de los "desaparecidos" que llaman desde algún punto en el interior de los que sobrevivieron; en Del sol naciente los muertos/víctimas renacen y en A Beata Maria do Egito los pobres gritan desde fuera de la escena, como un llamado de la Historia y de la realidad a las abstracciones del discurso oficial.

Pareciera que la historia política y social de nuestros pueblos se infiltra, sea cual sea la temática central, en estas palabras de mujeres postcoloniales y latinoamericanas.

Inés Margarita Stranger escribe y trabaja con un grupo de actrices el montaje de Cariño malo. Este tipo de construcción integrada se conecta con el sentido de la pieza, que se constituye como un ritual grupal feminista que puede representar el interior de una mujer/las mujeres en su lucha por la desconstrucción del sistema patriarcal. Estamos frente a la concepción del teatro como un laboratorio en el que se experimentan posibles estrategias de representación del "yo mujer". El programa de este laboratorio es la emergencia de una identidad femenina a partir de la enunciación plural (son tres que son una sola) y pública de la subjetividad femenina en proceso de afirmación. Esa zona privada sale a la luz a través de un acto de violencia - imaginaria - en la que, para afirmarse, es necesario matar al hombre, destruirlo corporalmente, mancharse con su sangre. Lo que se escenifica es el esfuerzo penoso de la mujer que tiene que reconstituirse después del "entierro" de todo lo que la constituía — inclu- 
sive del vestido blanco. No se trata de meramente enfrentar a la mujer a sus amores, sino de posibilitar una búsqueda en su interioridad de los discursos e imaginarios que la llevaron a la construcción de un "yo"que requiere de modo urgente de "otro" cualquiera masculino para ser "feliz" y facilitarle los medios para crear un "yo" diferente. La obra se construye - de modo consciente o no - como bandera de la lucha feminista y su manera de construirla colectivamente, inclusive con el público femenino ${ }^{6}$ cuestiona la propia naturaleza del teatro y posibilita un cambio en su concepción. Estamos hablando de un teatro de y para mujeres. Estamos hablando de un teatro que construye con el público una posible utopía: la de un amor asentado en bases igualitarias.

Estudiando estas tres enunciaciones, visualizamos el concepto de la diferencia en el discurso teatral latinoamericano. Sabemos que en América Latina conviven una pluralidad de identidades en las que la norma es la diferencia y en las que el territorio de origen de la enunciación - Brasil, Argentina, Chile permite cuestionar la idea de Nación como entidad monolítica y homogénea.? Se trata de generar una idea diferente de pertenencia a un medio, idea que tenga en cuenta los conceptos de género y subalternidad de los que hablamos al principio. Digamos que la idea de reescribir el canon y la historia literaria y cultural a partir de los trabajos producidos a la luz del concepto de género, se conjuga con la idea de territorialidad y de nuevas solidaridades. Una nueva historia de la cultura implica establecer una tradición que traiga al presente un pasado de palabras silenciadas y la creación de un diálogo entre voces diferentes.

Por otro lado, un desafío insistente en nuestro trabajo fue el pensar en una posible "pedagogía des(cons)tructiva" para América Latina, basándonos en la propuesta de Spivak, de hacer surgir nuevas formas de lectura y escritura, reivindicando la:

subjetividade das histórias alternativas acontecendo de um modo frequientemente não analisado. Uma pedagogia literária, com uma seleção cuidadosa de textos, pode ao menos preparar outro espaço que torne visíveis as lacunas dos slogans do iluminismo europeu - nacionalismo, internaciona-

6 El montaje realizado de esta obra en el teatro de la Pontificia Universidad Católica Chile, 1990, recibió el apoyo cerrado de las organizaciones feministas chilenas y de las mujeres que asistieron a las funciones.

7 Estos conceptos los podemos encontrar en ANDERSON y BHABHA.

CALIGRAMA - Belo Horizonte, 2:103-112 - novembro/1997 
lismo, secularismo, culturalismo, baluartes do nativismo - sem participar em sua destruição."

Terminamos reafirmando que el trabajo de esta antología, que ya tiene continuación en dos antologías más - una de poesía y otra de narrativa — aún en proceso de elaboración, es una toma de posición contra algunos de los presupuestos de la manutención de los procesos postcolonialistas de dominación por la enajenación del imaginario colectivo, que impide a los grupos subalternos levantar su voz:

Within the effaced itinerary of the subaltern subject, the track of sexual difference is doubly effected. The question is not of female participation in insurgency, or the ground rules of the sexual of division of labor, for both of which there is 'evidence'. It is, rather, that, both as object of colonialist historiography and as subject of insurgency, the ideological construction of gender keeps the male dominant. If, in the context of colonial production, the subaltern has no history and cannot speak, the subaltern as female is even more deeply in shadow..."

Pensamos que estos presupuestos determinan que las personas y pueblos vecinos vivan aislados no sólo en sus territorios y lenguas, sino también en sus pesadillas, problemas, crisis y conquistas - sin diálogo horizontal y sin intercambios profundos y permanentes. Sin la modificación de esta estructura se imposibilita el cambio. Citamos el último párrafo de la Introducción de la Antología:

creemos también que la libertad e independencia política, social y cultural de un pueblo, así como el avance, en términos cualitativos del ser humano, no puede asentarse en sistemas donde primen las desigualdades de cualquier tipo: ni de clase, ni de razas, ni tampoco de géneros. Mientras tanto, cualquier acción social que no tenga en cuenta estos postulados estará condenada al fracaso. ${ }^{\prime \prime}$

\footnotetext{
8 SPIVAK, 1994, p. 204.

9 SPIVAK, 1995, p. 28.

10 RAVETTI, G. y S. Rojo. Actualmente en publicación.
} 
RESUMO: Este artigo é um comentário à Antologia bilingue de dramaturgia de mulheres latino-americanas escrita por nós durante 1995-1996. A antologia escrita em português e espanhol é um estudo de três peças: A beata Maria do Egito de Rachel de Queiroz, Del sol naciente de Griselda Gambaro e Cariño malo de Inés Margarita Stranger. O artigo reflete sobre os fundamentos teóricos do trabalho realizado.

\section{REFERÊNCIAS BIBLIOGRÁFICAS}

GAMBARO, Griselda. Del Sol Naciente. Griselda Gambaro. Teatro I. Argentina: Ed. La Flor, 1984.

QUEIROZ, Rachel. A Beata Maria de Egito. Rio Janeiro: Livraria José Olympio, 1979. RAVETTI, G. Y S. ROJO. Antologia bilingue de dramaturgia de mulheres latinoamericanas. Belo Horizonte: Armazém de icléias/ CENEX FALE, 1996. . São Paulo: Editora Siciliano, 1995.

STRANGER, Inés. Cariño Malo. Revista Apuntes. Chile: U.C, 1999.

\section{BIBLIOGRAFIA CRÍTICA}

ANDERSON, Benedict. Imagined Communities. Reflections on the origen and spread of nationalism. London, New York: Verso, 1990. . Nação e consciência nacional. São Paulo: Atica, 1989.

ANDRADE/ CRAMSIE (Eds). Dramaturgas latinoamericanas contemporáneas. Verbum: Madrid, 1991.

BHABHA, Homi K. Nation and Narration. London: Routledge, 1990.

BORGES, J. L. "Otras inquisiciones” en Obras completas. Buenos Aires: EMECE, 1974.

CONTRERAS, Marta. "Las novelas grotescas de Griselda Gambaro", en: Escribir en los bordes. Congreso Internacional de Literatura Femenina Latinoamericana, Santiago: Editorial Cuarto Propio, 1987.

DIAZ-DIOCARETZ, Myriam y ZAVALA, Iris M. Breve historia feminista de la literatura española (en lengua castellana). Barcelona: Anthropos, 1993.

ELIOT, T.S. Selected Prose of T. S. Eliot. London: Faber and Faber, 1975.

FOUCAULT, Michel. História da Sexualidade: A vontade de saber. Trad. Maria Thereza da Costa Albuquerque, Rio de Janeiro: Graal, 1984.

JAMESON, Fredric. Ensayos sobre el posmodernismo. Argentina: Ed. Imago Mundi, 1991. 
MALLON, Florencia. "The promise and dilemma of Subaltern Studies: Perspectives from Latin American History"en American Historical Review. vol. 99, n5, Dezembro, 1994.

PAZ, Octavio. Cuadrivio. México: Joaquín Mortiz, 1965.

QUEIROZ, Isaura Maria Pereira de. O messianismo. No Brasil e no mundo. São Paulo: Alfa-Omega, 1976.

SPIVAK, G. "Can the Subaltern Speak?" en ASHCROFT, Bill, G. GRIFFTHS Y H. TIFFIN. The Post-Colonial Studies Reader: London a New York: Routledge, 1995. SPIVAK, G. "Quem reivindica a alteridade? " en BUARQUE DE HOLLANDA, H. (Ed.). Tendências e impasses. O feminismo como crítica da cultura. Rio de Janeiro: Rocco, 1994.

STORNI, Alfonsina. Antología poética. Buenos Aires: Ed. Losada, 1977. 